\title{
Sliding mode control-based system for the two-link robot arm
}

\author{
Trong-Thang Nguyen \\ Faculty of Energy Engineering, Thuyloi University, Vietnam
}

\begin{tabular}{l} 
Article Info \\
\hline Article history: \\
Received Jan 3, 2019 \\
Revised Mar 19, 2019 \\
Accepted Apr 2, 2019 \\
\hline Keywords: \\
Control structure \\
Robot arm \\
Sliding mode \\
Torque \\
Two-link
\end{tabular}

\begin{abstract}
In this research, the author presents the model of the two-link robot arm and its dynamic equations. Based on these dynamic equations, the author builds the sliding mode controller for each joint of the robot. The tasks of the controllers are controlling the Torque in each Joint of the robot in order that the angle coordinates of each link coincide with the desired values. The proposed algorithm and robot model are built on Matlab-Simulink to investigate the system quality. The results show that the quality of the control system is very high: the response angles of each link quickly reach the desired values, and the static error equal to zero.
\end{abstract}

Copyright @ 2019 Institute of Advanced Engineering and Science. All rights reserved.

Corresponding Author:

Trong-Thang Nguyen,

Faculty of Energy Engineering,

Thuyloi University,

175 Tay Son, Dong Da, Ha Noi, Viet Nam.

Email: nguyentrongthang@tlu.edu.vn

\section{INTRODUCTION}

The industrial robots were introduced in the 1950 s to replace human labor with the aim of improving the production efficiency and the quality of products. Some of the most popular robot tasks are as follows: painting, material handling, welding, manufacturing, and transportation, etc. Today, robots play an increasingly important role in industrial production. So, the performance development of robot applications is very important. There is much research about robot control such as [1-3], the most common technique is using the Proportional-Integral-Derivative controller. However, the dynamic equation of the robot is nonlinear. So, the PID controller is not suitable, the quality of the control system is not high.

There is some research about the nonlinear control of the robot such as the back-stepping control method $[4,5]$ the linearization technique $[6,7]$ etc. The disadvantage of these methods is the chattering phenomenon of the signal. The other techniques have been developed for robot control such as robust control [8, 9] optimal control [10, 11], adaptive control [12], and intelligent control [13, 14]. The disadvantage of these methods is that the calculation process of the controller is complicated. An effective and simple solution is applied based on the human operating experience is using the fuzzy control [15, 16], however, the sustainability is not high. To improve sustainability, the fuzzy control combined with the conventional PID controller has been proposed [17, 18]. However, the limitation of this solution is the output response is not fast.

To address the above limitations, in this research, the author proposes a sliding mode controller for the robot. Sliding Mode Controller is a powerful controller that can control both nonlinear and linear objects, has been studied by many researchers all the world especially in recent years. This control method was first proposed in early 1950 by Emelyanov and his co-workers. The advantages of the Sliding mode controller are the following: the robust and stable, good transient performances, the fast output response. Moreover, the control algorithm is simple and it is easy to set up the controller in practice. To remove the chattering 
phenomenon, the author adds a delay in the sliding surface. Finally, the author applies the proposed algorithm to control the two-link robot arm. The achieved results will be clearly demonstrated through the simulation on Matlab. The results will show that the quality of the control system is very high, the response angles of each link quickly reach the desired values, and there is not a static error.

\section{THE DYNAMIC EQUATION OF THE TWO-LINK ROBOR ARM}

The model of two-link robot arm is described as Figure 1. The symbols in Figure are as follows: $m_{1}$ and $l_{1}$ denotes the mass and lengths of Link1; $m_{2}, l_{2}$ denotes the mass and lengths of Link2; T1, T2 denotes the torque of Link1 and Link2; $\theta_{1}$ and $\theta_{2}$ denotes the link angles.

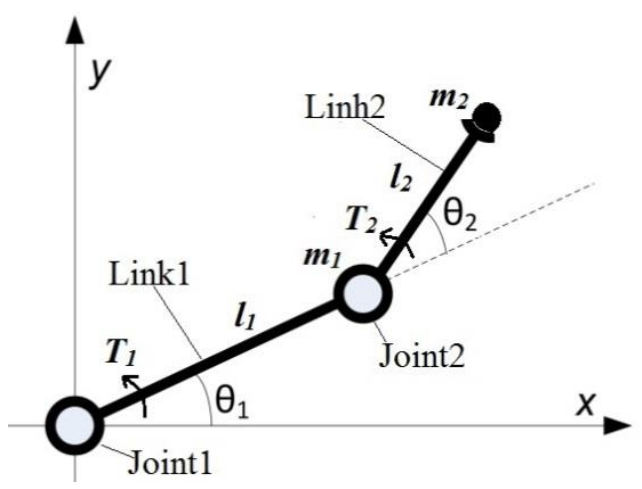

Figure 1. The two-link robot arm model

The dynamic equation of the two-link robot arm is represented by Euler-Lagrange system [19, 20] which is described as follows:

$$
\left[\begin{array}{l}
T_{1} \\
T_{2}
\end{array}\right]=\left[\begin{array}{ll}
D_{11} & D_{12} \\
D_{21} & D_{22}
\end{array}\right]\left[\begin{array}{l}
\ddot{\theta}_{1} \\
\ddot{\theta}_{2}
\end{array}\right]+\left[\begin{array}{l}
C_{1} \\
C_{2}
\end{array}\right]\left[\begin{array}{l}
\dot{\theta}_{1} \\
\dot{\theta}_{2}
\end{array}\right]+\left[\begin{array}{l}
G_{1} \\
G_{2}
\end{array}\right]
$$

where:

$D_{11}=\left(m_{1}+m_{2}\right) l_{1}^{2}+m_{2} l_{2}^{2}+2 m_{2} l_{1} l_{2} \cos \left(\theta_{2}\right)$

$D_{12}=D_{21}=m_{2} l_{2}^{2}+m_{2} l_{1} l_{2} \cos \left(\theta_{2}\right)$

$D_{22}=m_{2} l_{2}^{2}$

$C_{1}=-m_{2} l_{1} l_{2} \sin \left(\theta_{2}\right) \dot{\theta}_{2}-m_{2} l_{1} l_{2} \sin \left(\theta_{2}\right)\left(\dot{\theta}_{1}+\dot{\theta}_{2}\right)$

$C_{2}=m_{2} l_{1} l_{2} \sin \left(\theta_{2}\right) \dot{\theta}_{1}$

$G_{1}=\left(m_{1}+m_{2}\right) g l_{1} \cos \left(\theta_{1}\right)+m_{2} g l_{2} \cos \left(\theta_{1}+\theta_{2}\right)$

$G_{2}=m_{2} g l_{2} \cos \left(\theta_{1}+\theta_{2}\right)$

\section{THE DESIGN OF THE SLIDING MODE CONTROLLER FOR THE TWO-LINH ROBOT} ARM

Considering a n-order nonlinear object described by the equation:

$$
x^{(n)}(t)=f(x, t)+u(t)
$$

where: $x$ is the state variable, $u$ is the control signal.

Named $e$ is the error: $e=x_{s e t}-x$, with $x_{\text {set }}$ is the desired value, $x$ is the response value. 
Named:

$$
s=e^{(n-1)}+\lambda_{1} \cdot e^{(n-2)}+\ldots+\lambda_{n-2} \cdot \dot{e}+\lambda_{n-1} \cdot e
$$

The Equation $s=0$ is called sliding surface. Derivative (3), we have:

$$
\begin{aligned}
& \dot{s}=e^{(n)}+\lambda_{1} \cdot e^{(n-1)}+\ldots+\lambda_{n-2} \cdot e^{(2)}+\lambda_{n-1} \cdot \dot{e} \\
& =x_{s e t}{ }^{(n)}-x^{(n)}+\lambda_{1} \cdot e^{(n-1)}+\ldots+\lambda_{n-2} \cdot e^{(2)}+\lambda_{n-1} \cdot \dot{e}
\end{aligned}
$$

Replace $x^{(n)}(t)=f(x, t)+u(t)$ into the (4), we have:

$$
\dot{s}=x_{s e t}{ }^{(n)}-f(x, t)-u(t)+\lambda_{1} \cdot e^{(n-1)}+\ldots+\lambda_{n-2} \cdot e^{(2)}+\lambda_{n-1} \cdot \dot{e}
$$

Choosing the control signal $u$ in order that $\dot{s}=-K \operatorname{sign}(s)(K>0)$, we have:

$$
u=-f(x, t)+x_{s e t}^{(n)}+\lambda_{1} \cdot e^{(n-1)}+\ldots+\lambda_{n-2} \cdot e^{(2)}+\lambda_{n-1} \cdot \dot{e}+K \cdot \operatorname{sign}(s)
$$

Setting Lyapunov function $V=\frac{1}{2} s^{2}$. If $u$ is designed by the control law (6), then $\dot{s}=-K . \operatorname{sign}(s)$. We have:

$$
\dot{V}=s . \dot{s}=-K \cdot|s|<0 \quad \forall s
$$

Therefore, the system will stabilize asymptotically at the equilibrium point $s=0$, mean that e and all n-derivatives of $e$ will reach zero. Applying the sliding mode control for the two-link robot arm that is a twoorder nonlinear object:

$$
\ddot{x}=f(x, t)+u(t)
$$

where:

$$
\begin{aligned}
& x=\theta=\left[\begin{array}{l}
\theta_{1} \\
\theta_{2}
\end{array}\right] \\
& u=\left[\begin{array}{l}
T_{1} \\
T_{2}
\end{array}\right] \\
& \text { The error }
\end{aligned}
$$

Choosing the sliding surface:

$$
s=\left[\begin{array}{l}
s_{1} \\
s_{2}
\end{array}\right]=\dot{e}-\lambda e
$$


where:

$$
\lambda=\left[\begin{array}{l}
\lambda_{1} \\
\lambda_{2}
\end{array}\right] \text { is the coefficient of the sliding surface. }
$$

Applying the (6), the control rule of the two-link robot arm is as follows:

$$
u=-f(x, t)+\theta_{\text {set }}+\lambda \cdot \dot{e}+K \cdot \operatorname{sign}(s)
$$

where $K=\left[\begin{array}{l}K_{1} \\ K_{2}\end{array}\right]$ is the coefficient of the controller.

\section{THE RESULTS AND ANALYSIS}

Based on the model presented in Figure 1, the author builds the model of the two-link robot arm on Matlab-Simulink, as shown in Figure 2.

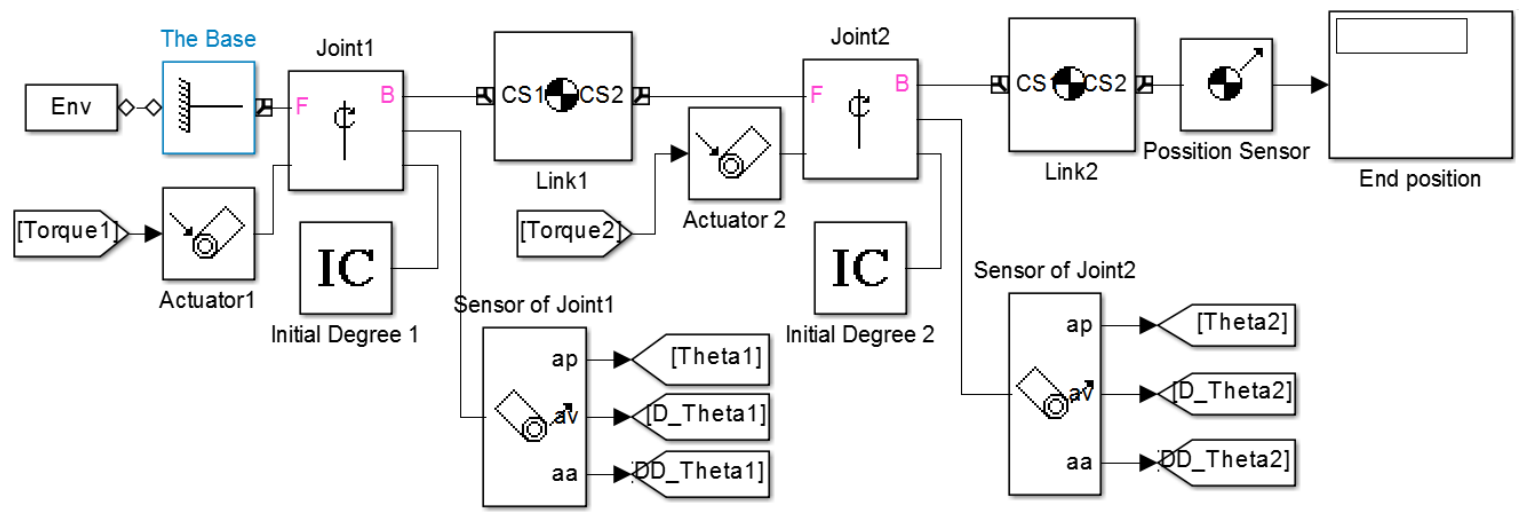

Figure 2. The model of the two-link robot arm on Matlab

Robot parameters are installed as follows: $l_{l}=1(\mathrm{~m}) ; m_{l}=0.8(\mathrm{~kg}) ; l_{2}=0.5(\mathrm{~m}) ; m_{2}=0.4(\mathrm{~kg})$. The initial angles:

$$
\theta=\left[\begin{array}{l}
\theta_{1} \\
\theta_{2}
\end{array}\right]=\left[\begin{array}{l}
-\pi / 6 \\
-\pi / 8
\end{array}\right](\mathrm{rad})
$$

The controller is designed according to Equation (8), its diagram is shown in Figure 3. The parameters of the sliding mode controller are set as follows:

$$
\lambda=\left[\begin{array}{l}
5 \\
5
\end{array}\right] ; K=\left[\begin{array}{l}
10 \\
9
\end{array}\right]
$$

Running the system, in the case function $\dot{s}=K \cdot \operatorname{sign}(s)$, we get the results that are shown as Figure 4, Figure 5 and Figure 6. Figure 4 shows the phase-status trajectories of joint 1 and joint 2. The simulation results show that all status trajectories go to the origin $O(0,0)$. Thus, the response angles $(\theta)$ are going to the desired values $\left(\theta_{\text {set }}\right)$. 


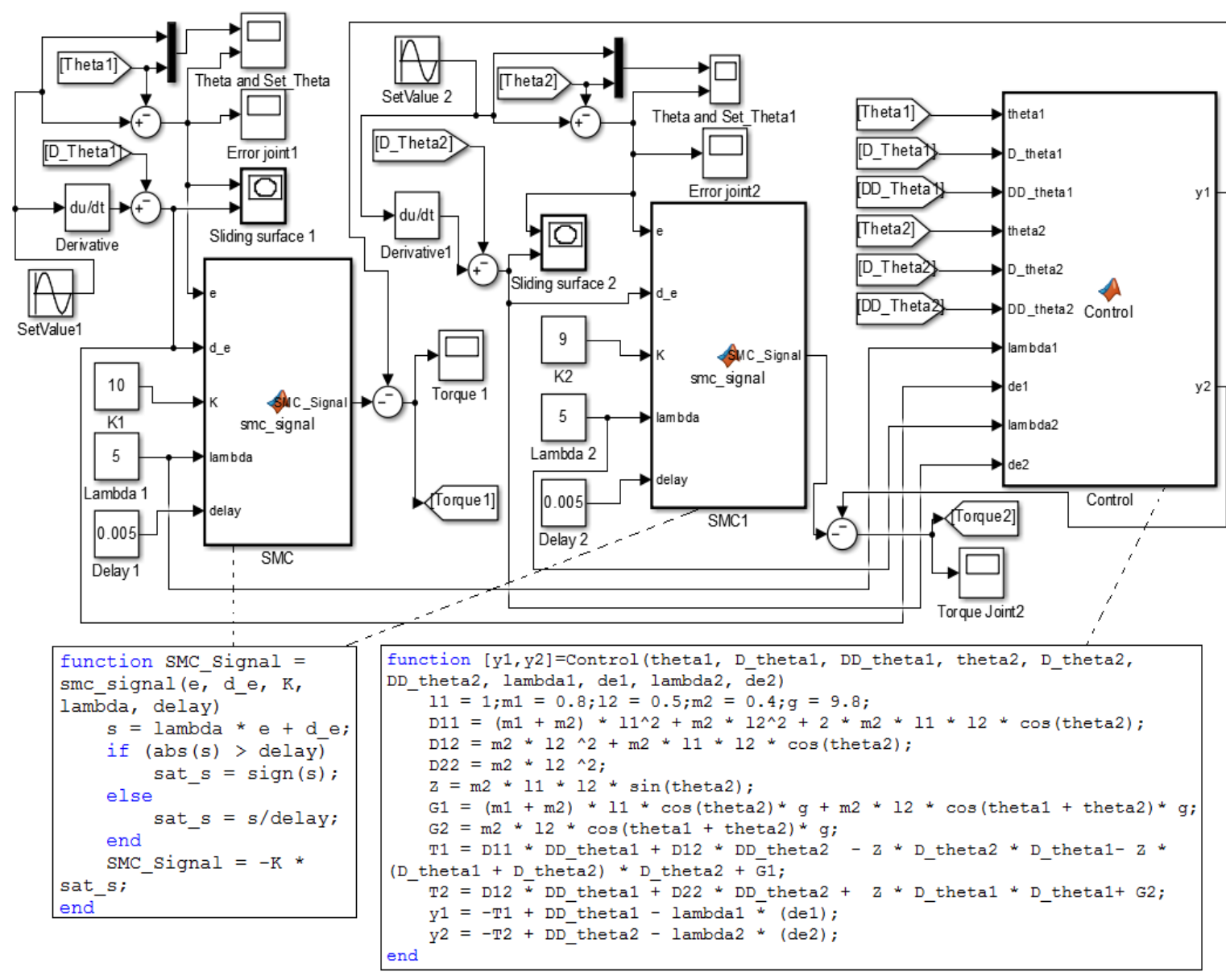

Figure 3. The model of controller

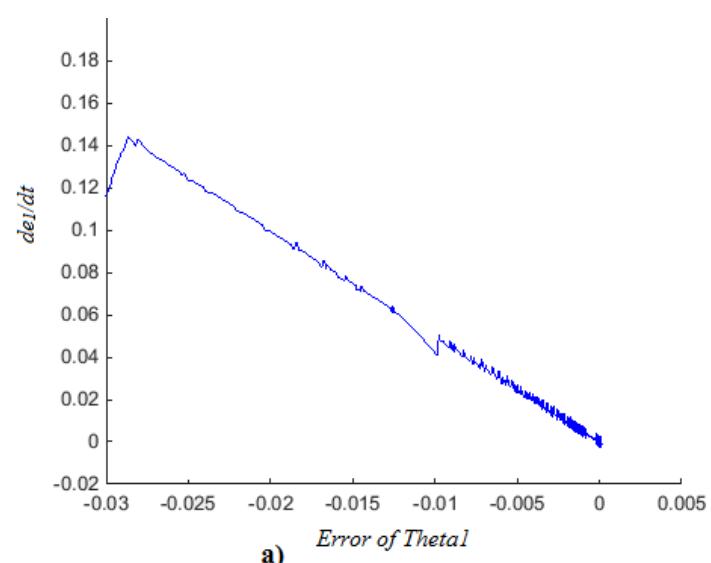

a)

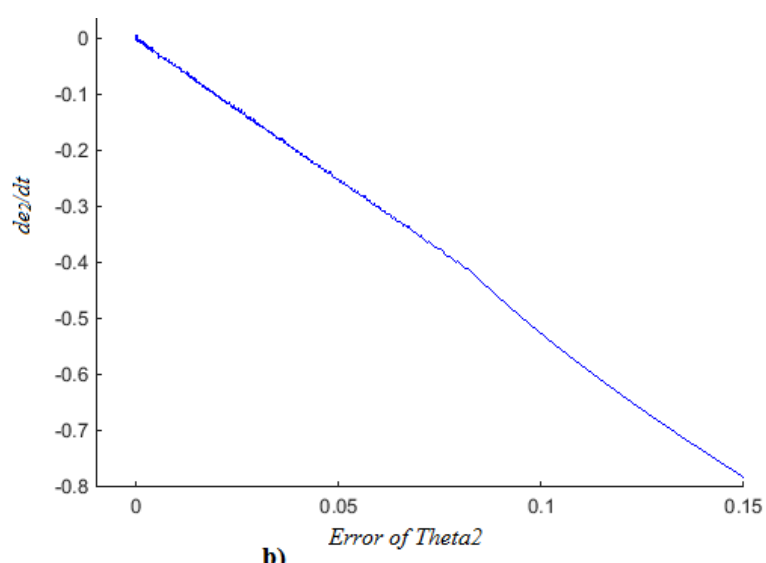

b)

Figure 4. The phase-status trajectories in the case $\dot{s}=K \operatorname{sign}(s):$ a) the joint1, b) the joint2

Figure 5 shows the time characteristics of the desired angles $\left(\theta_{1_{-} s e t}, \theta_{2_{-} s e t}\right)$, the response angles $\left(\theta_{1}, \theta_{2}\right)$, and the errors $\left(e_{1}, e_{2}\right)$. The simulation results show that: Initially, the desired angles and the response angles are not equal, after a short period of time (about 1.5s) the response angles meet the desired angle, then the response angles always match the desired angle, the errors $\left(e_{1}, e_{2}\right)$ are equal to zero. Therefore, we can confirm that the quality of the control system is very good. The control torque of each joint is shown in Figure 6. 

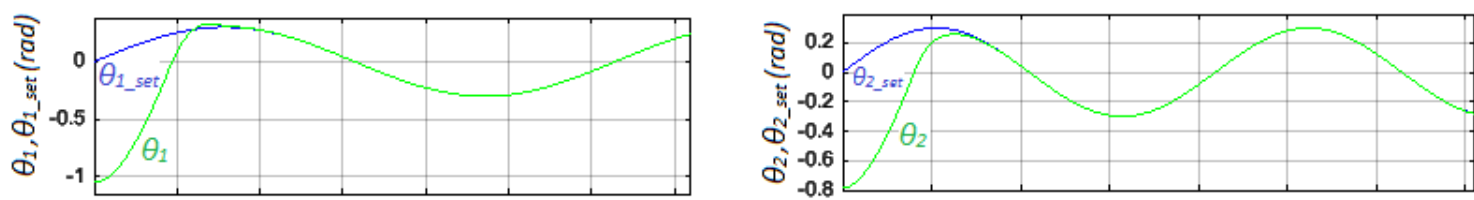

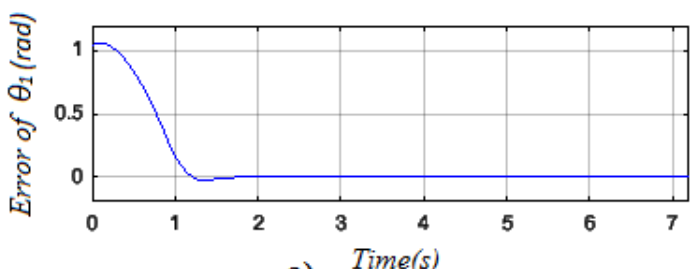

a) $\operatorname{Time}(s)$

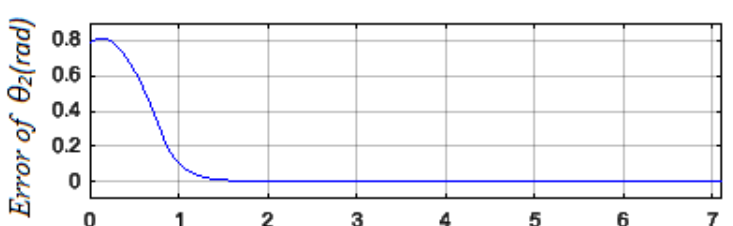

b) $\operatorname{Time}(s)$

Figure 5. The time characteristics in the case $\dot{s}=K \cdot \operatorname{sign}(s):$ a) the joint1, b) the joint 2

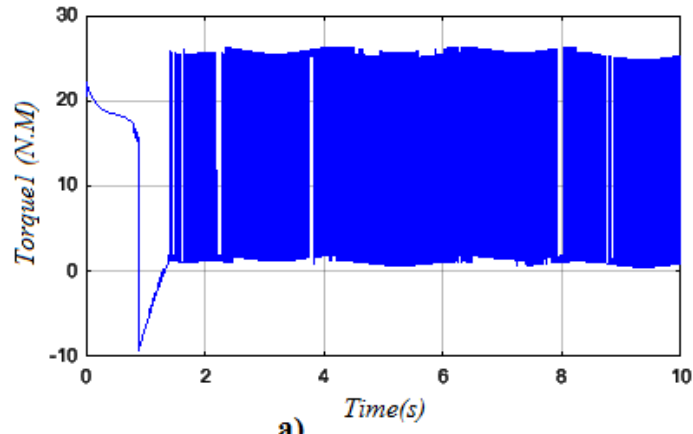

a)

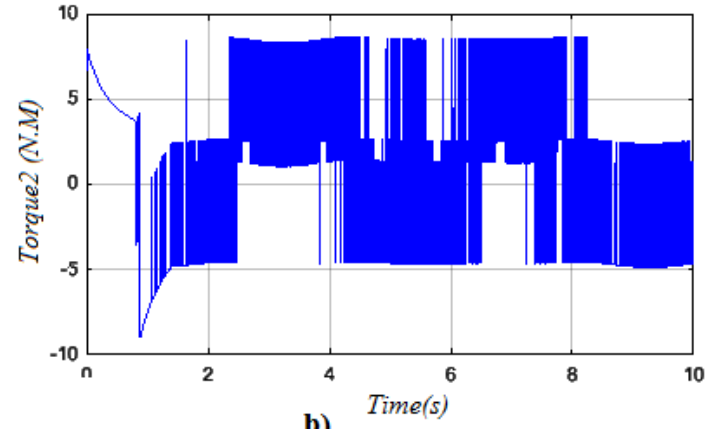

b)

Figure 6 . The torque of each joint in the case $\dot{s}=K \cdot \operatorname{sign}(s):$ a) the joint 1 ; b) the joint2

The simulation results show that the torque's chattering phenomenon is high, which negatively affect the system, making the lifespan of the actuator and equipment reduce. To overcome this limitation, we add the delay into the function $(\dot{S})$, so the function $(\dot{S})$ is converted to the following:

$$
\dot{s}_{i}=K_{i} \cdot \operatorname{sat}\left(s_{i}\right)=\left(\begin{array}{l}
K_{i} \cdot \operatorname{sign}\left(s_{i}\right) \text { if }\left|s_{i}\right|>d \\
K_{i} \cdot \frac{s_{i}}{d} \text { if }\left|s_{i}\right| \leq d
\end{array} \quad(i=1,2)\right.
$$

where $d$ is the delay, setting $d=0.005$. In the case $\dot{S}_{i}=K_{i} \cdot \operatorname{sat}\left(s_{i}\right)$, the simulation results are shown in Figure 7-9. Figure 7 shows the phase-status trajectories of each joint. We see that the phase-status trajectories go straight to the origin coordinates without the oscillation. Thus, the system quality has been improved.

Figure 8 shows the time characteristics of the desired angles $\left(\theta_{1_{-} \text {set }}, \theta_{2_{-} s e t}\right)$, the response angles, and the errors $\left(e_{1}, e_{2}\right)$. The simulation results show that although we add the delay, the quality of the system is still very good, the response angles always equal to the desired angles with the error of zero. Figure 9 shows that the chattering phenomenon of each joint torque is greatly reduced, which is essential for the system to ensure the actuators and devices are sustainable. 


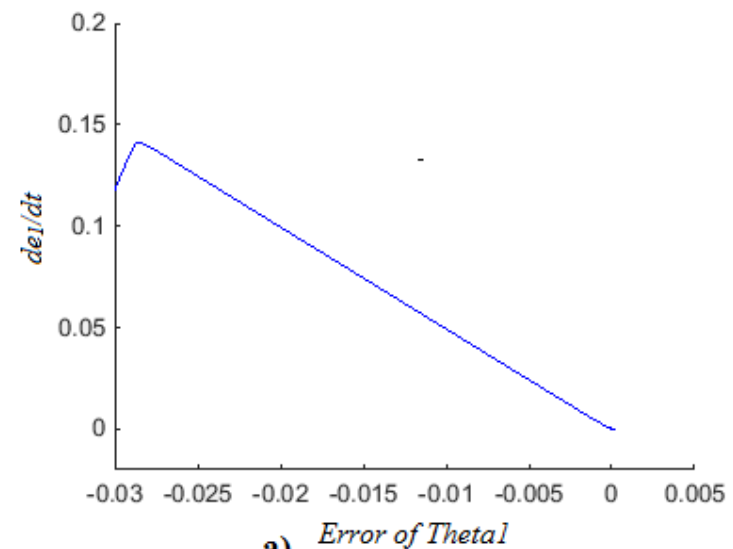

a) Error of Thetal

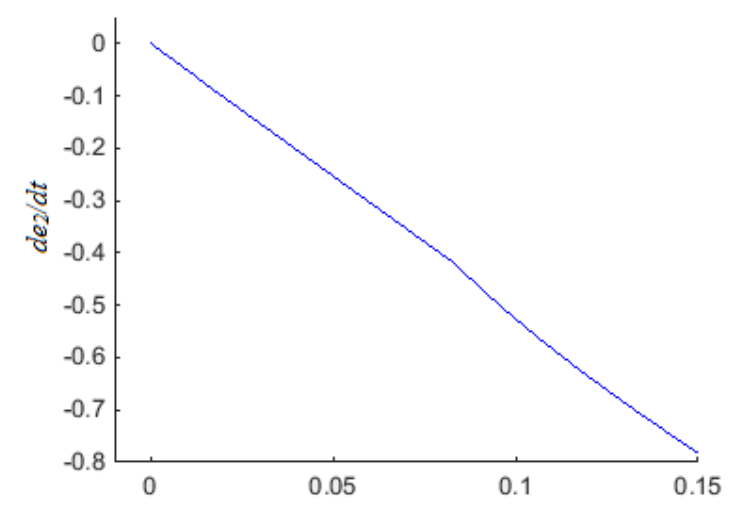

b)

Figure 7. The phase-status trajectory in the case $\dot{S}_{i}=K_{i} \cdot \operatorname{sat}\left(s_{i}\right):$ a) the joint1, b) the joint2
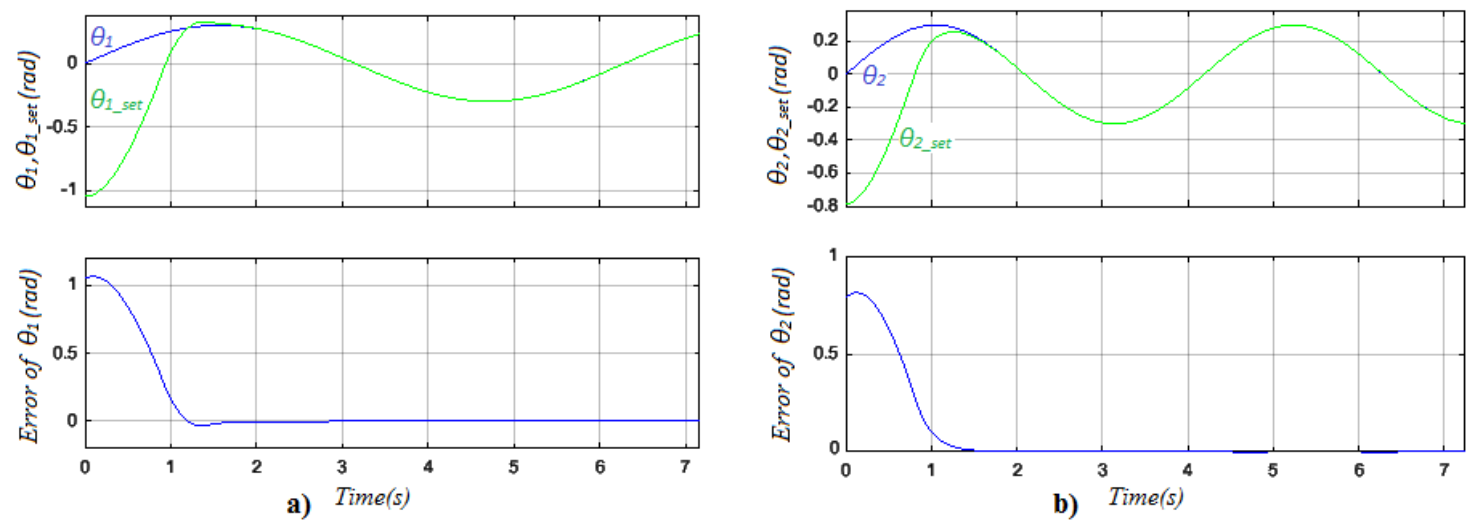

Figure 8 . The time characteristics in the case $\dot{S}_{i}=K_{i} \cdot \operatorname{sat}\left(s_{i}\right):$ a) the joint 1, b) the joint 2
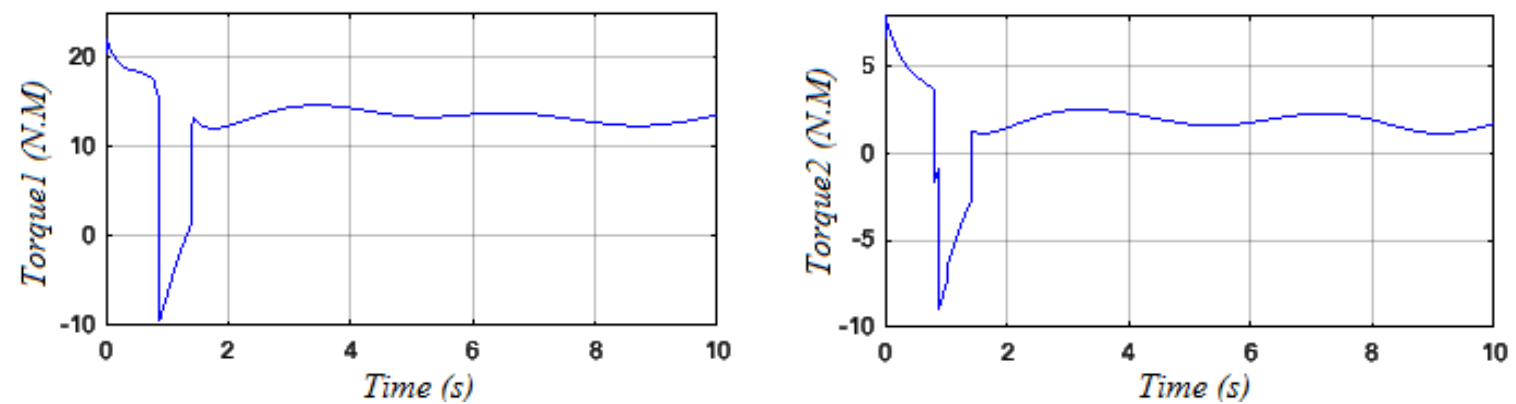

Figure 9 . The torque of each joint in the case $\dot{S}_{i}=K_{i} \cdot \operatorname{sat}\left(s_{i}\right):$ a) the joint 1 ; b) the joint2

\section{CONCLUSION}

In this study, the author has succeeded in building the sliding mode controller for the two-link robot arm. The simulation results show that the quality of the system is very high, the angle coordinates of the links always follow the desired values in a short time, and there is no static error. Especially in the case $\dot{s}_{i}=K_{i} \cdot \operatorname{sat}\left(s_{i}\right)$, the chattering phenomenon of each joint torque is greatly reduced, thus increasing the lifespan of the controller and actuator. The control algorithms are simple, presented in detail, so it is easy to build the proposed controller in practice. 


\section{REFERENCES}

[1] I. David and G. Robles, "PID control dynamics of a Robotic arm manipulator with two degrees of Freedom," Control de Processos y Robotica, 17th August, pp. 3-7, 2012.

[2] P. Rocco, "Stability of PID control for industrial robot arms," IEEE transactions on robotics and automation, vol/issue: 12(4), pp. 606-614, 1996.

[3] J. Y. Dieulot and F. Colas, "Robust PID control of a linear mechanical axis: A case study," Mechatronics, vol/issue: 19(2), pp. 269-273, 2009.

[4] M. N. Kamarudin, et al., "New robust bounded control for uncertain nonlinear system using mixed backstepping and lyapunov redesign," International Journal of Electrical and Computer Engineering (IJECE), vol/issue: 9(2), 2019.

[5] M. R. Soltanpour and M. M. Fateh, "Sliding mode robust control of robot manipulator in the task space by support of Feedback Linearization and Back Stepping Control," World Applied Sciences Journal, vol/issue: 6(1), pp. 70-76, 2009.

[6] F. J. C. Garcia, et al., "On the Design of a 4 Degrees-of-Freedom Pick and Place Cable Suspended Parallel Manipulator," IAES International Journal of Robotics and Automation (IJRA), vol/issue: 6(4), 2017.

[7] T. J. Tarn, et al., "Effect of motor dynamics on nonlinear feedback robot arm control," IEEE Transactions on Robotics and Automation, vol/issue: 7(1), pp. 114-122, 1991.

[8] M. R. Soltanpour, et al., "Robust nonlinear control of robot manipulator with uncertainties in kinematics, dynamics and actuator models," International Journal of Innovative Computing, Information and Control, vol/issue: 8(8), pp. 5487-5498, 2012.

[9] F. Harashima, et al., "Practical robust control of robot arm using variable structure system," Proceedings. 1986 IEEE International Conference on Robotics and Automation, vol. 3, pp. 532-539, 1986.

[10] S. Kumar, "Robotic Arm Movement optimization using soft Computing," IAES International Journal of Robotics and Automation (IJRA), vol/issue: 6(1), 2017.

[11] S. Kumar, et al., "Robotic Arm Movement Optimization Using Soft Computing," IAES International Journal of Robotics and Automation (IJRA), vol/issue: 6(1), pp. 1-14, 2017.

[12] W. Ham, "Adaptive control based on explicit model of robot manipulator," IEEE transactions on automatic control, vol/issue: 38(4), pp. 654-658, 1993.

[13] S. Nurmaini and B. Tutuko, "Intelligent Robotics Navigation System: Problems, Methods, and Algorithm," International Journal of Electrical and Computer Engineering (IJECE), vol/issue: 7(6), pp. 3711-3726, 2017.

[14] R. Koker and A. Ferikoglu, "Model based intelligent control of a 3-joint robotic manipulator: A simulation study using artificial neural networks," International Symposium on Computer and Information Sciences, Springer, Berlin, Heidelberg, pp. 31-40, 2004.

[15] A. Mayub and F. Fahmizal, "Center of Pressure Feedback for Controlling the Walking Stability Bipedal Robots using Fuzzy Logic Controller," International Journal of Electrical and Computer Engineering (IJECE), vol/issue: 8(6), 2018.

[16] G. C. Hwang and S. C. Lin, "A stability approach to fuzzy control design for nonlinear systems," Fuzzy sets and Systems, vol/issue: 48(3), pp. 279-287, 1992.

[17] S. J. Huang and J. S. Lee, "A stable self-organizing fuzzy controller for robotic motion control," IEEE Transactions on Industrial Electronics, vol/issue: 47(2), pp. 421-428, 2000.

[18] J. L. Meza, et al., "Fuzzy Self-Tuning PID Semiglobal Regulator for Robot Manipulators," IEEE Trans. Industrial Electronics, vol/issue: 59(6), pp. 2709-2717, 2012.

[19] T. N. Trong and M. N. Duc, "Sliding Surface in Consensus Problem of Multi-Agent Rigid Manipulators with Neural Network Controller,” Energies, vol/issue: 10(12), pp. 2127, 2017.

[20] R. M. Murray, "A mathematical introduction to robotic manipulation," CRC press, 2017. 